\title{
Experiment Research of UHMWPE Fiber Reinforced Concrete under Triaxial Compression
}

\author{
Lingfeng $\mathrm{Li}^{1, \mathrm{a}}$, Luhui Yan ${ }^{1, \mathrm{~b}}$ and Yuwu Zhang ${ }^{2, \mathrm{c}}$ \\ ${ }^{1}$ National University of Defense Technology, Changsha 410072, China; \\ ${ }^{2}$ Engineering College, The University of Nottingham, Nottingham NG7 2RD, UK. \\ alilingfeng13@tinghua.org.cn, 'byanluhui2002@163.com, 'zhangyuwu2013@163.com
}

Keywords: UHMWPE fiber reinforced concrete, triaxial compression experiment, stress-strain curve, strength, compression toughness.

\begin{abstract}
A triaxial compression test was carried out to investigate the effect of ultra high molecular weight polyethylene (UHMWPE) on concrete's behavior, in which four kinds of fiber volume fraction $(0 \%, 0.3 \%, 0.5 \%, 1.0 \%)$ and five kinds of confining pressure (0MPa, 3MPa, $6 \mathrm{MPa}$, $12 \mathrm{MPa}, 18 \mathrm{MPa}$ ) were designed. The experiment result shows that both confining pressure and fiber volume fraction have influences on the stress-strain curves of the fiber reinforced concrete where the confining pressure's improvement will increase peak stress and mixing fiber will increase limit strain. According to that, a formula is given to describe the relationship between the strength of UHMWPE fiber reinforced concrete, confining pressure and fiber volume fraction. Then by using compression toughness index method, the relationship between the toughness of UHMWPE fiber reinforced concrete, confining pressure and fiber volume fraction is also revealed. When the confining pressure is $18 \mathrm{MPa}$ and the fiber volume fraction is beyond $0.5 \%$, the toughness improvement is the most remarkable.
\end{abstract}

\section{Introduction}

UHMWPE owns many excellent properties, like high strength, high modulus, chemical resistance, impact resistance, incision resistance etc. , which has the lowest density among the high modulus soft fibers in the world [1]. Relevant researches [2 4] show that mixing UHMWPE into concrete can increase the impact toughness and tensile strength significantly, which will improve the penetration resistance property. During actual engineering applications, concrete is always in complex stress conditions. When under triaxial compression, concrete will show an improvement in strength and toughness, which means uniaxial compression or tension test would not satisfy the demand of complex stress condition analysis and design. Some research [5 8] has been conducted to investigate the mechanical behavior of steel fiber reinforced concrete under triaxial compression, however there is no relevant research in UHMWPE fiber reinforced concrete.

In order to recognize the effect of UHMWPE on concrete under triaxial compression, we used MTS 815 test machine to give five kinds of confining pressure (0MPa, 3MPa, 6MPa, $12 \mathrm{MPa}$, $18 \mathrm{MPa})$ on UHMWPE fiber reinforced concrete in four kinds of fiber volume fraction $(0 \%, 0.3 \%$, $0.5 \%, 0.7 \%$ ), respectively. Through analyzing the stress-strain curves, the influences of fiber volume fraction and confining pressure on concrete's compression properties are researched systematically. The conclusions are helpful for building the constitutive model of UHMWPE fiber reinforced concrete in next step of research.

\section{Experiment Preparation}

2.1 Materials and Mix Proportion. Cement is P.O 42.5 Portland cement, which comes from Zhe Jiang South Cement Company. Coarse aggregate is well graded with grain diameter between 5 to $10 \mathrm{~mm}$. Fine aggregate comes from Xiang Jiang, which fineness modulus is 2.5 and apparent density is $2.68 \mathrm{~g} / \mathrm{cm}^{3}$. Tiny silicon powder is produced by $\mathrm{Hu}$ Nan Saibort Building Material Company, which specific surface area is $25000 \mathrm{~m}^{2} / \mathrm{Kg}$ and bulk density is $200 \sim 250 \mathrm{Kg} / \mathrm{m}^{3}$. 
Naphthalene water reducer is adopted which water-reducing rate is $26.5 \%$. Water comes from water supply company. UHMWPE is made by Hu Nan Zhongtai Company, which properties are shown in Tab. 1.

Tab. 1 UHMWPE fiber physical and mechanical properties index

\begin{tabular}{cccccc}
\hline $\begin{array}{c}\text { Diameter } \\
/ \mu \mathrm{m}\end{array}$ & $\begin{array}{c}\text { Length } \\
/ \mathrm{mm}\end{array}$ & $\begin{array}{c}\text { Density } \\
/ \mathrm{g} \cdot \mathrm{m}^{-3}\end{array}$ & $\begin{array}{c}\text { Tensile strength } \\
/ \mathrm{MPa}\end{array}$ & $\begin{array}{c}\text { Elasticity modulus } \\
/ \mathrm{GPa}\end{array}$ & $\begin{array}{c}\text { Limit ductility } \\
/ \%\end{array}$ \\
\hline 60 & 30 & 0.97 & 3000 & 100 & 2.8 \\
\hline
\end{tabular}

Mix proportion is: water cement ratio 0.326 , sand ratio $40 \%$, water reducer ratio $1.6 \%$, tiny silicon powder ratio $9.5 \%$. The specific mix proportion is shown in Tab. 2.

Tab. 2 Concrete mix proportion

\begin{tabular}{ccccccccc}
\hline \multirow{2}{*}{ Code } & $V_{f} / \%$ & Water & Cement & Aggregate & Sand & $\begin{array}{c}\text { Tiny silicon } \\
\text { powder }\end{array}$ & $\begin{array}{c}\text { Water } \\
\text { reducer }\end{array}$ & UHMWPE \\
\hline T0 & 0 & 185 & 547 & 936 & 615 & 57.5 & 12 & 0 \\
T3 & 0.3 & 185 & 547 & 936 & 615 & 57.5 & 12 & 2.91 \\
T5 & 0.5 & 185 & 547 & 936 & 615 & 57.5 & 12 & 4.85 \\
T7 & 0.7 & 185 & 547 & 936 & 615 & 57.5 & 12 & 6.79 \\
\hline
\end{tabular}

$* V_{f}$ represents fiber volume fraction and $\rho$ represents the mass in unit volume.

2.2 Test Machine and Specimens. MTS 815 rock triaxial test system, made by America, is adopted as the test machine. The highest uniaxial load range of this system is $4600 \mathrm{KN}$ and highest confining load range is $140 \mathrm{MPa}$, with $\pm 0.5 \%$ measuring precision. It can give out stress-strain curve, elasticity modulus and poisson ratio of concrete specimens under different confining pressure accurately.

According to the test machine, the size of the specimens was designed to be $950 \mathrm{~mm} \times 100 \mathrm{~mm}$ cylinder and all the specimens were divided into twenty groups. Each group had five specimens, which had same fiber volume fraction and confining pressure. Three of them were tested and the rest of two were standby. After vibrating and modeling, they were kept into standard conserving room for 28 days.

The test method of this research is according to CECS13-2009 [9].

\section{Results and Analysis}

3.1 Stress-strain Curves. The typical stress-strain curves are shown in Fig. 1. According to lecture [10], the stress-strain curve of concrete under triaxial compression can be divided into four stages: elasticity, stress soften, strain soften and damage. For UHMWPE fiber reinforced concrete, from 0 stress to $85 \%$ peak stress, the curve is in elasticity. After that to peak stress, the stress becomes soft with the strain's growth. Then the stress reduces with the strain's continuing growth which called strain soften until damage.

The effect of confining pressure mainly shows in strength. Along with the improving in confining pressure, the peak stress of fiber concrete grows. It can be seen that for the plain concrete, the peak stress under $18 \mathrm{MPa}$ confining pressure is 2.33 times of that under 0MPa confining pressure. At the same time, confining pressure changes the elasticity modulus in a certain extent during elasticity stage. The affect extent also depends on the fiber volume fraction. For 18MPa confining pressure, the elasticity modulus of each fiber volume fraction differs apparently.

The effect of fiber volume fraction mainly shows in ductility. On one hand, the limit strain of fiber reinforced concrete is always higher than that of plain concrete under any confining pressure. This indicates that mixing UHMWPE fiber could improve the concrete's ductility. On the other hand, it is not true that the bigger the fiber volume fraction is, the higher the limit strain is. It also depends on the confining pressure. This shows that fiber volume fraction and confining pressure have synergistic effect on concrete's ductility. 


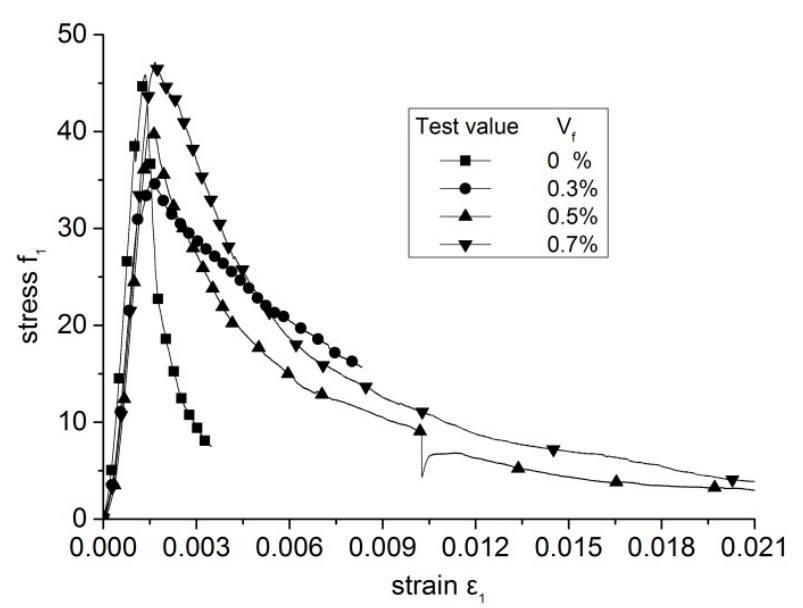

(a) Confining pressrure $\mathrm{f}_{3}=0 \mathrm{MPa}$

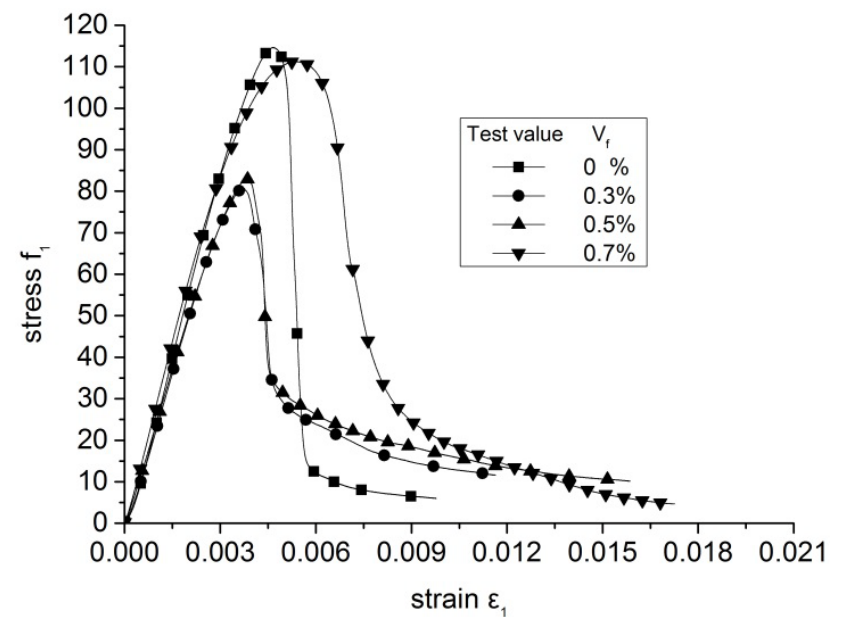

(c) Confining pressrure $\mathrm{f}_{3}=12 \mathrm{MPa}$

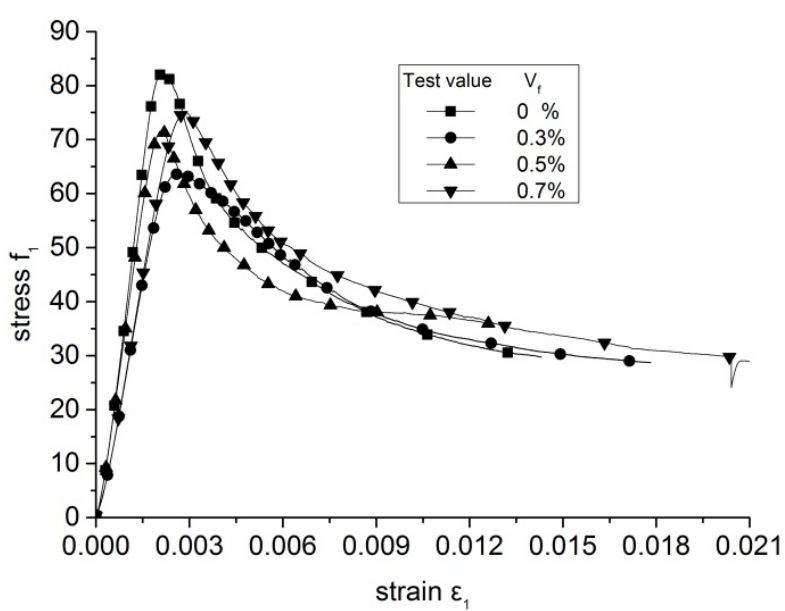

(b) Confining pressrure $\mathrm{f}_{3}=3 \mathrm{MPa}$

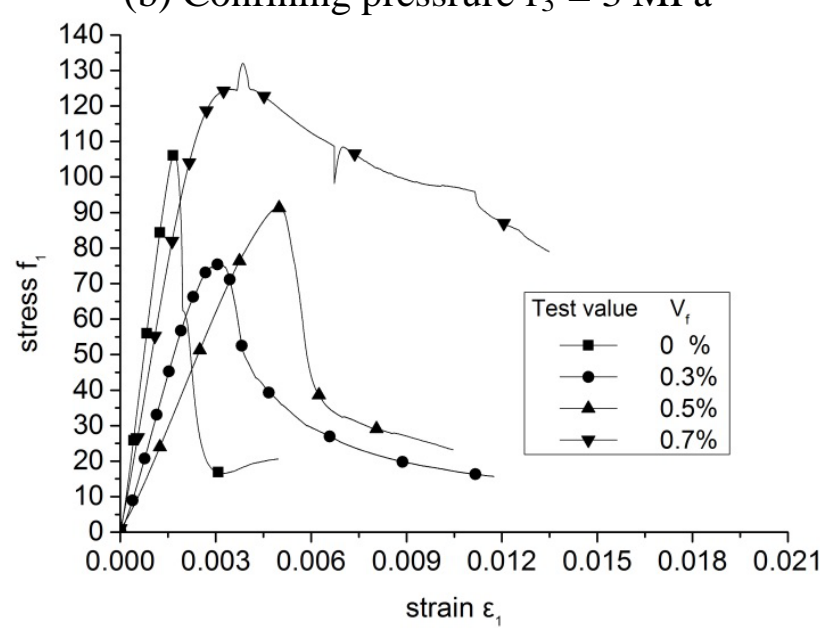

(d) Confining pressrure $\mathrm{f}_{3}=18 \mathrm{MPa}$

Fig. 1 Stress-strain curves under different confining pressure

3.2 Strength Characteristic. The strength characteristics of specimens with different fiber volume fraction under different confining pressure are shown in Tab. 3, from which we can see that confining pressure and fiber volume fraction both have affection in concrete's strength. By using formula (1), the relationship between strength and confining pressure for each fiber volume fraction can be fitted, respectively. Then the value of A and B are calculated in Tab. 4 and the fitting curves are drawn in Fig. 2 (a).

$$
\frac{f_{1}}{f_{0}}=1+A\left(\frac{f_{3}}{f_{0}}\right)^{B}
$$

The fitting curves show that formula (1) can reflect the relationship between strength and confining pressure of UHMWPE fiber reinforced concrete very well. However, it can be seen that different fiber volume fraction has different value of A and B. Through observing, we found that quadratic function could fit the relationship between A (B) and fiber volume fraction well. The fitting formulas are shown in formula (2) and formula (3) while the fitting curves are shown in Fig. 3.

$$
\begin{aligned}
& A=2.04-5.14 V_{f}+9.29 V_{f}^{2} \\
& B=0.33-1.03 V_{f}+2.06 V_{f}^{2}
\end{aligned}
$$

By using formula (2) and formula (3), the value of $\mathrm{A}$ and $\mathrm{B}$ for each fiber volume fraction are calculated again as $A_{0}$ and $B_{0}$, respectively. Then in formula (1), $A$ is replaced by $A_{0}$ while $B$ is replaced by $\mathrm{B}_{0}$ for each fiber volume fraction and the fitting curves are drawn again, which are shown in Fig. 2 (b). Comparing the new fitting curves with the test values, we can find that new fitting curves can also reflect the relationship between strength and confining pressure very well. Thus, considering formula (1), (2) and (3), formula (4) is found to reflect the relationship between the strength of UHMWPE fiber reinforced concrete, confining pressure and fiber volume fraction. 


$$
\frac{f_{1}}{f_{0}}=1+\left(2.04-5.14 \mathrm{~V}_{f}+9.29 \mathrm{~V}_{f}^{2}\right)\left(\frac{f_{3}}{f_{0}}\right)^{\left(0.33-1.03 \mathrm{~V}_{f}+2.06 \mathrm{~V}_{f}^{2}\right)}
$$

Tab. 3 Strength and deformation characteristic value under triaxial compression

\begin{tabular}{cccccccccc}
\hline $\begin{array}{c}\mathrm{V}_{\mathrm{f}} \\
(\%)\end{array}$ & Code & $\mathrm{f}_{3} / \mathrm{f}_{0}$ & $\mathrm{f}_{1} / \mathrm{f}_{0}$ & $\eta_{c 3}$ & $\begin{array}{c}\mathrm{V}_{\mathrm{f}} \\
(\%)\end{array}$ & Code & $\mathrm{f}_{3} / \mathrm{f}_{0}$ & $\mathrm{f}_{1} / \mathrm{f}_{0}$ & $\eta_{c 3}$ \\
\hline \multirow{6}{*}{0} & $\mathrm{~T} 0-1$ & 0.00 & 1.00 & 3.80 & & $\mathrm{~T} 5-1$ & 0.00 & 1.00 & 5.88 \\
0 & $\mathrm{~T} 0-2$ & 0.07 & 1.79 & 5.25 & & $\mathrm{~T} 5-2$ & 0.08 & 1.80 & 5.02 \\
& $\mathrm{~T} 0-3$ & 0.13 & 1.96 & - & 0.5 & $\mathrm{~T} 5-3$ & 0.15 & 1.83 & 5.46 \\
& $\mathrm{~T} 0-4$ & 0.26 & 2.50 & - & & $\mathrm{T} 5-4$ & 0.30 & 2.08 & 3.13 \\
& $\mathrm{~T} 0-5$ & 0.39 & 2.33 & 2.88 & & $\mathrm{~T} 5-5$ & 0.45 & 2.29 & - \\
& $\mathrm{T} 3-1$ & 0.00 & 1.00 & 6.31 & & $\mathrm{~T} 7-1$ & 0.00 & 1.00 & 5.90 \\
& $\mathrm{~T} 3-2$ & 0.09 & 1.84 & 5.54 & & $\mathrm{~T} 7-2$ & 0.06 & 1.59 & 5.13 \\
0.3 & $\mathrm{~T} 3-3$ & 0.17 & 1.95 & 4.05 & 0.7 & $\mathrm{~T} 7-3$ & 0.13 & 1.72 & 5.44 \\
& $\mathrm{~T} 3-4$ & 0.35 & 2.32 & 3.21 & & $\mathrm{~T} 7-4$ & 0.25 & 2.36 & 3.62 \\
& $\mathrm{~T} 3-5$ & 0.52 & 2.19 & 4.02 & & $\mathrm{~T} 7-5$ & 0.38 & 2.64 & 5.31 \\
\hline
\end{tabular}

$* \mathrm{f}_{3}$ represents confining pressure, $\mathrm{f}_{1}$ represents compressive strength, $\mathrm{f}_{0}$ represents compressive strength under uniaxial compression and $\eta_{c 3}$ represents compression toughness index.

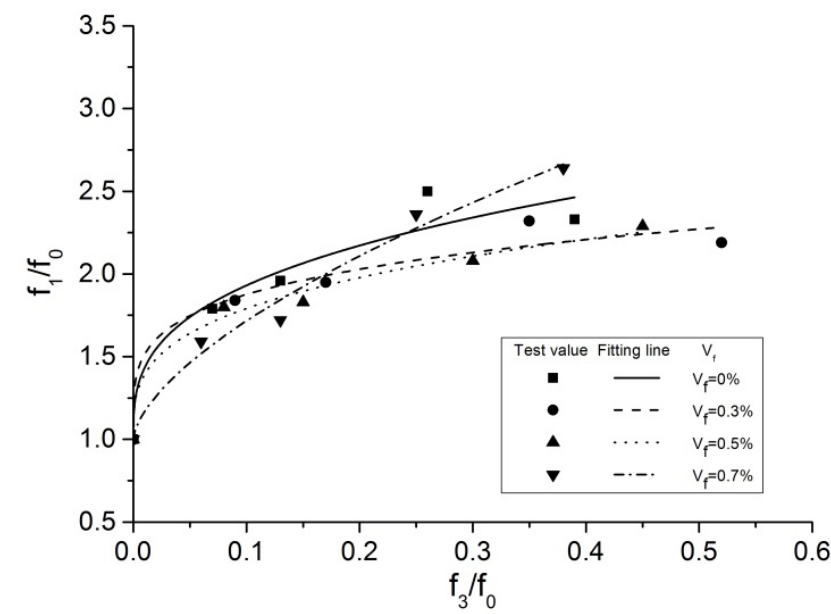

(a) Fitting curves by using A and B

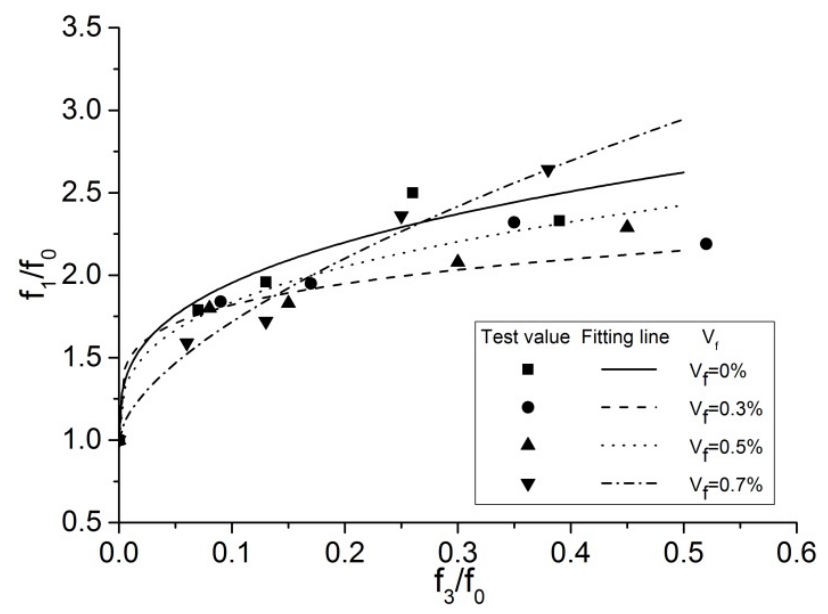

(b) Fitting curves by using $\mathrm{A}_{0}$ and $\mathrm{B}_{0}$

Fig. 2 Fitting curves of the relationship between strength and confining pressure

3.3 Compression Toughness. There are many ways to indicate material's compression toughness, among which compression toughness index method is the most common in engineering [11]. In the up stage of stress-strain curve, 0.85 times of peak stress is called critical stress and the corresponding strain is called critical strain. Through using area which is surrounded by stress-strain curve and 3 times of critical strain to divide area which is surrounded by stress-strain curve and critical strain, the value got is called $\eta_{c 3}$. According to that definition, the $\eta_{c 3}$ of UHMWPE fiber reinforced concrete under each fiber volume fraction and confining pressure is calculated in Tab. 3 . Linear fit the relationship of $\eta_{c 3}$ with fiber volume fraction and confining pressure, which is shown in Fig. 4, respectively. 
Tab.4 Characteristic value of fitting formula

\begin{tabular}{ccccc}
\hline $\begin{array}{c}\mathrm{V}_{\mathrm{f}} \\
(\%)\end{array}$ & $\mathrm{A}$ & $\mathrm{B}$ & $\mathrm{A}_{0}$ & $\mathrm{~B}_{0}$ \\
\hline 0 & 2.00 & 0.33 & 2.04 & 0.33 \\
0.3 & 1.49 & 0.23 & 1.33 & 0.21 \\
0.5 & 1.60 & 0.31 & 1.79 & 0.33 \\
0.7 & 3.06 & 0.63 & 2.99 & 0.62 \\
\hline
\end{tabular}

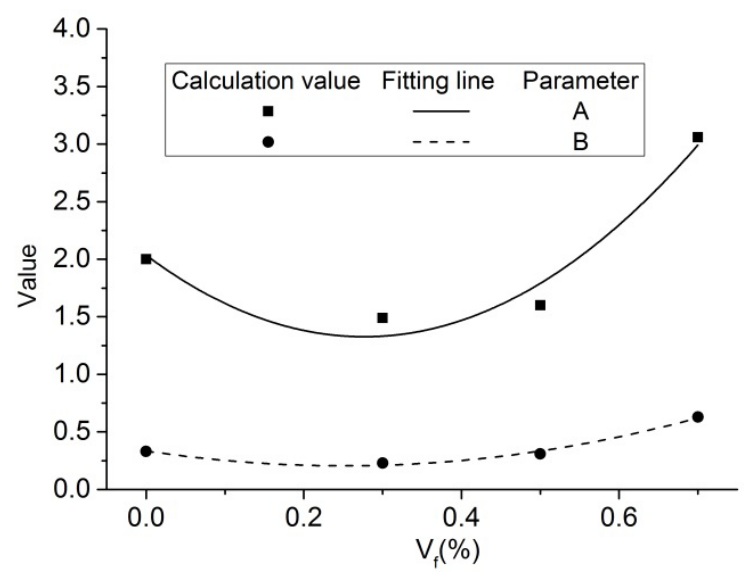

Fig. 3 Fitting curves of parameter A and B

It can be seen that confining pressure and fiber volume fraction have different affection in concrete's compression toughness. On the one hand, along with the confining pressure's growth, the $\eta_{c 3}$ gets down. However, different fiber volume fraction has different decline rate. When fiber volume fraction is between $0.3 \% \sim 0.5 \%$, the decline rate is the fast. On the other hand, along with the fiber volume fraction's growth, the $\eta_{c 3}$ gets up in a whole. Apparently, when the confining pressure gets $18 \mathrm{MPa}$, the increase rate is the fast. Thus, it can be concluded that the effect of confining pressure and fiber volume fraction on concrete is not absolutely. There is a reasonable range for confining pressure and fiber volume fraction which could lead a most increasement in the compression toughness of concrete.

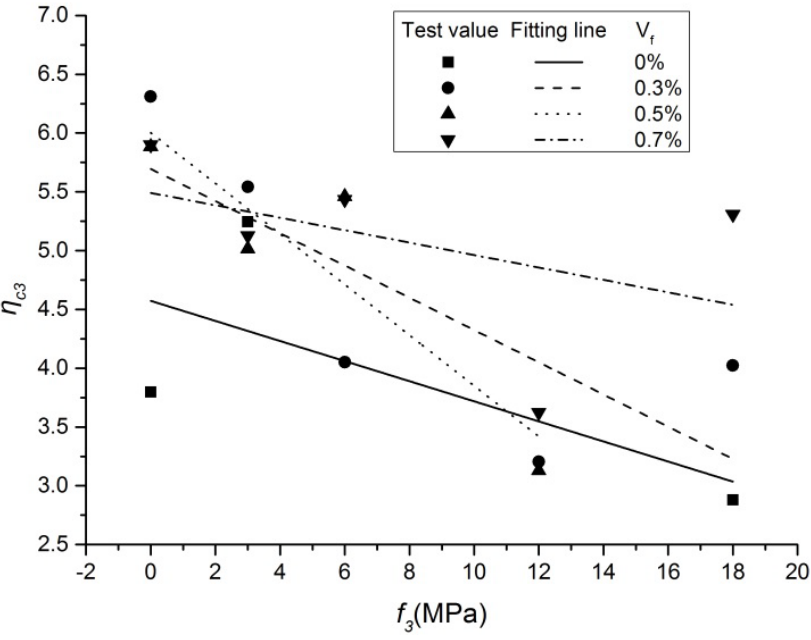

(a) Fitting lines of $\eta_{\mathrm{c} 3}$ and confining pressure

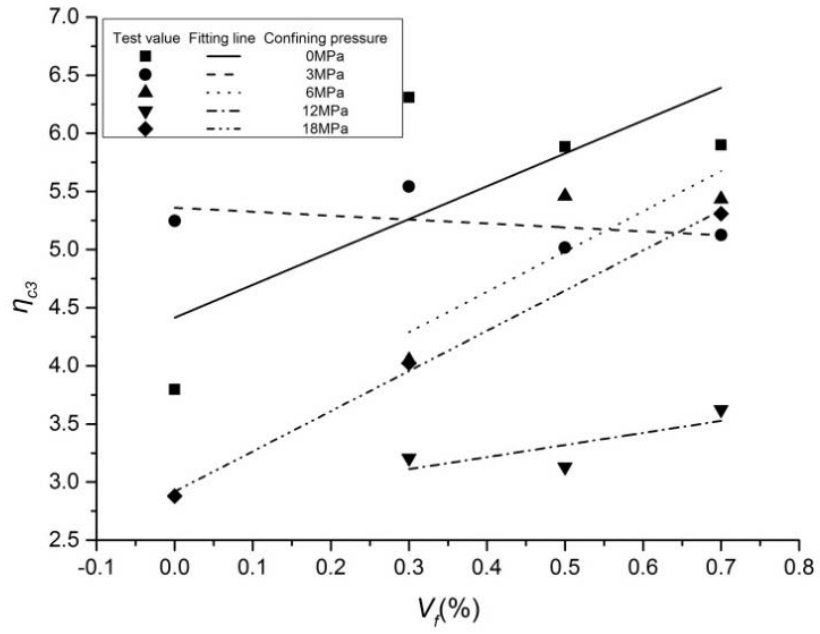

(b) Fitting lines of $\eta_{\mathrm{c} 3}$ and fiber volume fraction Fig. 4 Fitting lines of $\eta_{\mathrm{c} 3}$ with confining pressure and fiber volume fraction

\section{Conclusion}

(a) The stress-strain curve of UHMWPE fiber reinforced concrete has typical 4 stages. Confining pressure affects the strength mainly. The bigger confining pressure is, the bigger peak stress is. Besides that, the elasticity modulus of concrete in different fiber volume fraction differs apparently. 
Mixing fiber could improve concrete's limit strain and confining pressure has synergistic effect on concrete's ductility.

(b) By using power function, the relationship between strength and confining pressure is fitted. Then by using quadratic function, the relationship between fiber volume fraction and parameter of the power function is fitted. Finally, the formula (4) is got to describe the relationship between strength, confining pressure and fiber volume fraction, which suits the test values well.

(c) Adopt compression toughness index method to estimate the effect of confining pressure and fiber volume fraction on compression toughness of UHMWPE fiber reinforced concrete. Along with the confining pressure's growth, the compression toughness goes down. The decline extent depends on the fiber volume fraction. Increase of fiber volume fraction will lead improvement in compression toughness. The improvement extent depends on the confining pressure. 18MPa confining pressure and over $0.5 \%$ fiber volume fraction is the best for compression toughness's improvement.

\section{References}

[1] Y. Zhang, H. Zhou, N.C. Yang, The application of ultra high molecular weight polyethylene fiber in bulletproof and puncture-proof materials, Textile Science Research, (2009) No.4, p.16-26.

[2] Y.W. Zhang, L.H. Yan, L. Zhu, Experiment research on mechanical properties and penetration performance of UHMWPE fiber concrete, Advanced Materials Research, Vol. 989-994 (2014), p.961-965.

[3] B.H. Ji, J.M. Gao, X. Dong, Research in organic synthesis fiber reinforced high performance light aggregate concrete, China Concrete and Cement Products, (2004) No.5, p.45-47.

[4] L.H. Yan, Y.W. Zhang, L. Zhu, Basic mechanical properties of ultra high molecular weight polyethylene fiber concrete, Journal of National University of Defense Technology, Vol. 36 (2014) No.6, p.43-47.

[5] Y.P. Song, G.P. Zhao, F. Peng et al, Strength behavior and failure criterion of steel fiber concrete under triaxial stresses, China Civil Engineering Journal, Vol. 27 (1994) No.3, p.14-23.

[6] Z.L. Wang, B. Chu, Strength and toughness characteristic of steel fiber reinforced concrete in triaxial compression, Journal of Building Materials, Vol. 15 (2012) No.3, p.301-305.

[7] C. Xu, G. Peng, Y.L. Qi et al, Experimental study on dynamic characters of steel fiber reinforced concrete under triaxial pressure, Concrete, (2011) No.6, p.23-25.

[8] X.L. Liu, S.F. Liu, B.D. Qin, Experimental study on strength and deformation feature of hybrid fiber high-strength concrete under conventional triaxial compression, Journal of Henan Polytechnic University (Natural Science), Vol. 32 (2013) No.2, p.226-229.

[9] CECS 13-2009: Standard Test Methods for Fiber Reinforced Concrete (China Planning Press, China 2010).

[10] P.Y. Song, G.P. Zhao, F. Peng, Deformation behavior of steel fiber reinforced concrete under triaxial stresses, Journal of Hydraulic Engineering, (1995) No.5, p.1-8.

[11] B. Ji: Experimental study and numerical simulation on static and dynamic compressive behavior of 3-D braid steel fiber reinforced concrete (Ph.D., Nanjin University of Aeronautics and Astronautics, China 2011). 